\title{
Long-Term Effects of Segmental Lumbar Spinal Fusion on Adjacent Healthy Discs: A Finite Element Study
}

\author{
Gunti Ranga Srinivas ${ }^{1}$, Anindya Deb ${ }^{1}$, Malhar N. Kumar ${ }^{2}$, Goutham Kurnool ${ }^{1}$ \\ ${ }^{1}$ Center for Product Design and Manufacturing, Indian Institute of Science, Bangalore, India \\ ${ }^{2}$ Department of Orthopaedics, HOSMAT Hospital, Bangalore, India
}

\section{Study Design: Experimental study.}

Purpose: The aim of the study was to develop a finite element (FE) model to study the long-term effects of various types of lumbar spinal interventions on the discs adjacent to the fused segment.

Overview of Literature: Earlier FE studies have been limited to one particular type of fusion and comparative quantification of the adjacent disc stresses for different types of surgical interventions has not been reported.

Methods: A computer aided engineering (CAE) based approach using implicit FE analysis assessed the stresses in the lumbar discs adjacent to the fused segment following anterior and posterior lumbar spine fusions at one, two and three levels (with and without instrumentation).

Results: It was found that instrumentation and length of fusion were the most significant factors in increasing adjacent level stresses in the lumbar discs.

Conclusions: In the present study, a calibrated FE model that examined spinal interventions under similar loading and boundary conditions was used to provide quantitative data which would be useful for clinicians to understand the probable long-term effect of their choice of surgical intervention.

Keywords: Lumbar vertebrae; Spinal fusion; Intervertebral disc; Intervertebral disc degeneration

\section{Introduction}

Segmental spinal fusion has been widely employed in the management of degenerative disc disease of the lumbar spine. The disadvantage of fusion is that pain relief is achieved at the cost of elimination of existing range of movement in the affected segment. Ehni [1] observed as early as 1981 that "fusion generates a conflict between immediate benefit and late consequences". Intermediate and long-term follow-up studies have shown the onset of degenerative changes in the intervertebral discs adjacent to the fused segment $[2,3]$. In the series of patients with adjacent segment degeneration (ASD) reported by Lee, the changes had become clinically manifest between 1 year and 38 years following the index operation [4]. Radiological changes of ASD may be either asymptomatic or associated with clinical symptoms in the affected patients [5]. Depending on the length of follow-up, the incidence

Received Aug 29, 2015; Revised Nov 14, 2015; Accepted Nov 30, 2015

Corresponding author: Malhar N Kumar

Department of Orthopaedics, HOSMAT Hospital, Bangalore, India

Tel: +91-093426-33667, Fax: +91-00918025593796, E-mail: docmnkumar@gmail.com 
of radiographic ASD has been reported to vary from 5.2\% to $100 \%$. Park et al. [6] reported that the incidence of clinically symptomatic ASD varied from $5.2 \%$ to $18.5 \%$. Kumar et al. [7] presented that $36 \%$ of ASDs change after a mean of 5.2 years and $50 \%$ of patients with ASD required reoperation. Ghiselli et al. [8] found a re-operation rate of $27.4 \%$ at an average of 6.7 years following the index surgery. Gillet [9] reported $41 \%$ incidence of ASD and that $20 \%$ required reoperation i.e., extension of fusion.

Though ASD has been reported following different types of surgical interventions, it is not clear whether certain types of these interventions were associated with higher magnitudes of ASD than others. FE studies reported earlier have been limited to one particular type of fusion and comparative quantification of the stresses in the adjacent discs has not been reported following different types of lumbar spinal fusions [10]. In the present study finite element analysis has been used to study the effect of different types of lumbar surgical interventions on the stresses in the adjacent lumbar discs. The magnitudes of stresses in the adjacent segment under different interventional conditions have been quantified. This provides surgeons a quantitative estimate of the magnitude of the adjacent disc stresses that the proposed surgical intervention is likely to cause.

\section{Materials and Methods}

\section{A primary FE model of a truncated vertebral unit}

A 3D finite element model of the lumbar spine was generated from computed tomography scan images of the human subject using biomechanical modeling software
(Materialize, Leuven, Belgium). Finite element models of the truncated vertebral units (TVUs) were then developed to generate the force-displacement response under quasi-static compressive loading conditions. An advanced implicit FE Software LS-DYNA was used in the present study. The FE model of L2-L3 TVU is shown in Fig. 1A. The cortical bone and the end plates were modeled with shell elements, the cancellous bone of the vertebral body along with the inter-vertebral disc were modeled using solid elements. The TVU was rested on the bottom plate and the bottom plate was rigidly fixed in all six-displacement degrees of freedom. A vertical displacement was given to the top plate to simulate quasi-static axial compression as shown in Fig. 1B.

\section{Experimental validation of the TVU FE model}

A specimen of the lumbar spine was harvested from a fresh frozen 45-year old male cadaver. The soft tissues and the posterior elements were removed to leave only the TVU. Experimental characterizations of the elasto-plastic behavior of the L1-L2 TVU and L2-L3 TVU under quasistatic axial compressive loading were then carried out. The TVU under axial compression is shown in Fig. 2. The force-displacement response under quasi-static loading conditions was obtained from the experimental testing of the two truncated lumbar spine specimens.

In the present study, mechanical behaviors of the various tissues modeled in Fig. 1A were represented with piecewise linear plasticity formulation in LS-DYNA using MAT 24. The mechanical properties of the tissues, namely elastic modulus, Poisson's ratio, and strength were obtained from the literature $[10,11]$ and from tests carried
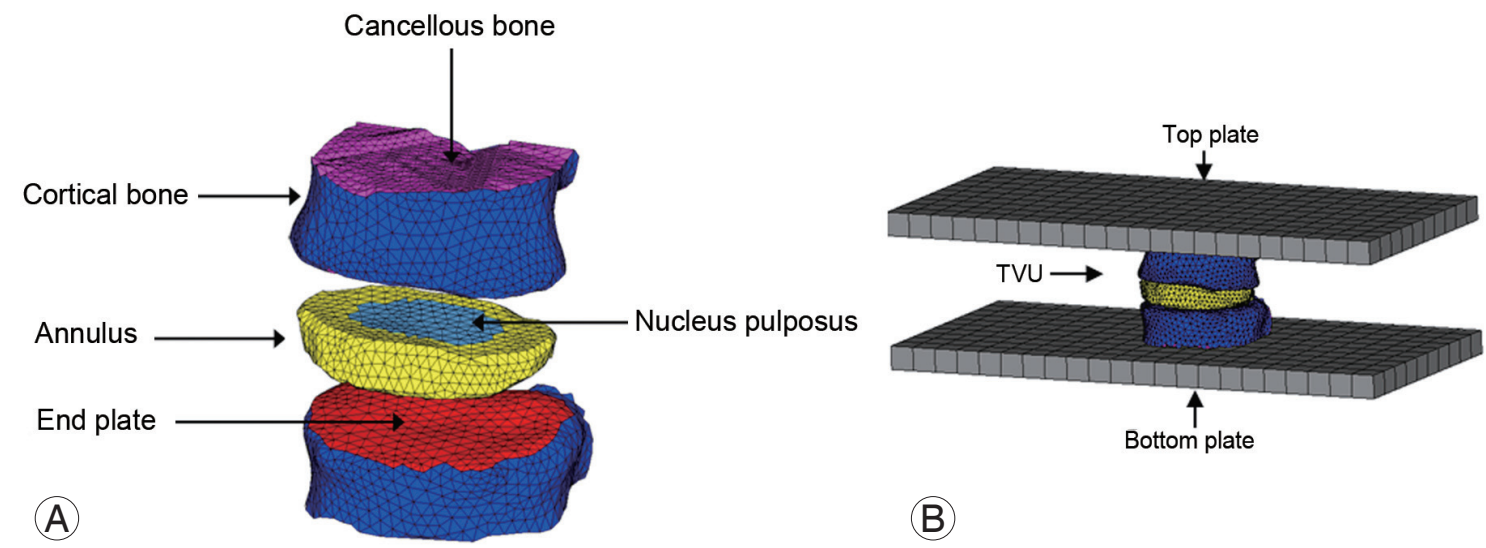

(B)

Fig. 1. (A) Finite element model of the truncated vertebral unit (TVU, exploded view); (B) TVU under quasi static compression. 
out in an Universal Testing Machine on samples extracted from the vertebral body of the tested specimen (Table 1). The variation of the sectional force generated between the top plate and the TVU with respect to the corresponding vertical displacement of the plate, which was obtained

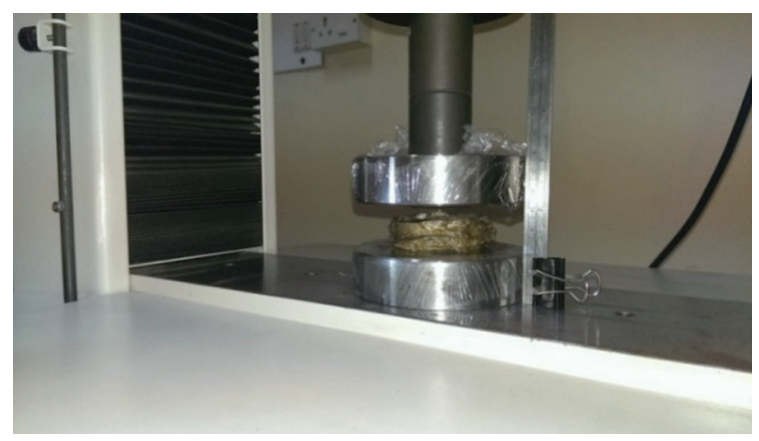

Fig. 2. Test setup.
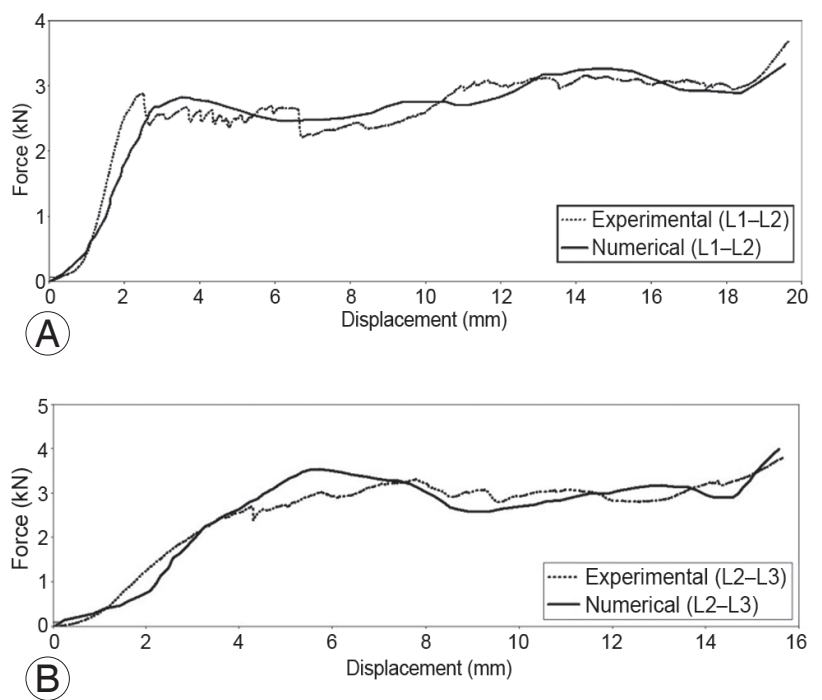

Fig. 3. A comparison of experimental and numerically computed loaddisplacement behaviors of TVUs under quasi-static axial compression (A) L1-L2 TVU; (B) L2-L3 TVU. TVU, truncated vertebral unit. from $\mathrm{FE}$ analysis, was compared with the experimental force-displacement curve as shown in Fig. 3. It can be seen from the figure that the computed force-displacement curves are in good agreement with the results obtained from the experimental tests.

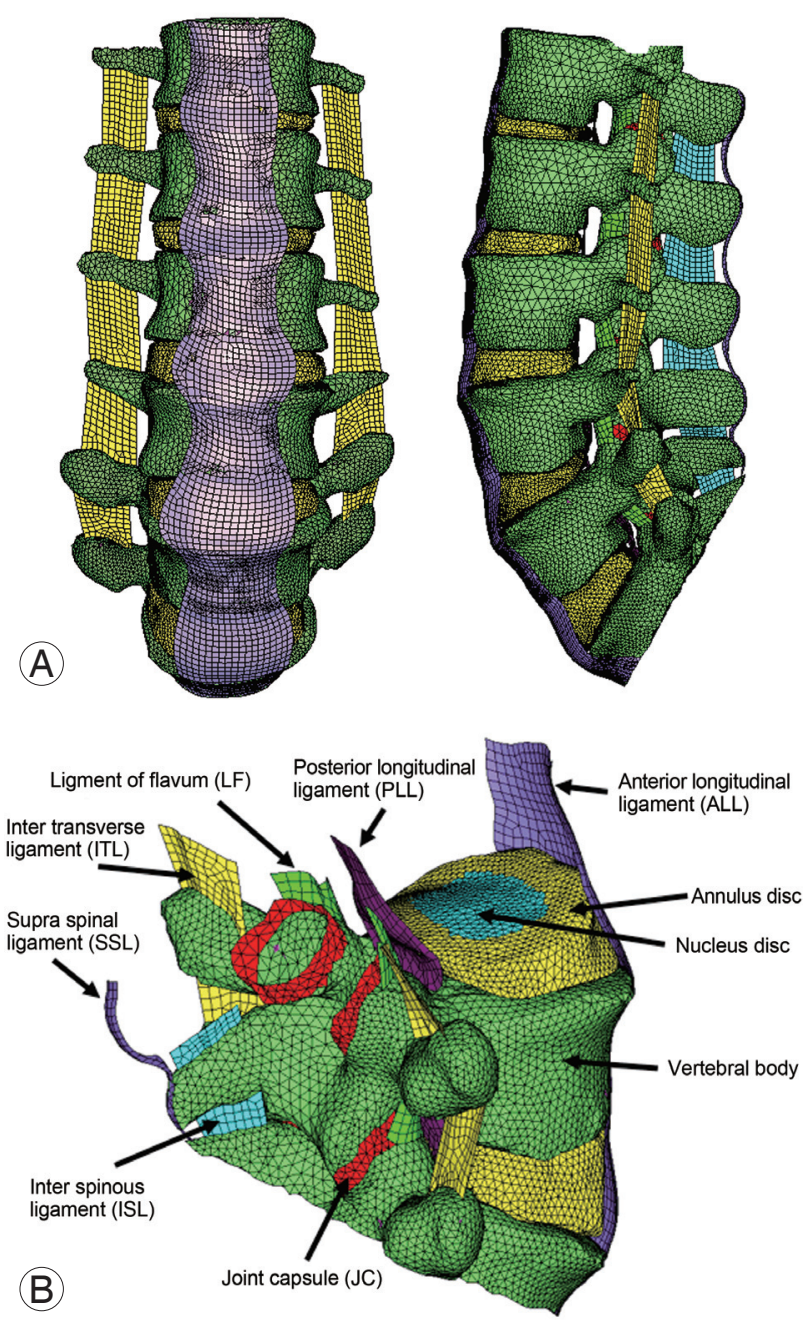

Fig. 4. (A) Definitive FE model of the lumbar spine; (B) Bony and soft tissue components included in the FE model. FE, finite element.

Table 1. Material properties of bony vertebral elements and discs

\begin{tabular}{|c|c|c|c|c|}
\hline \multirow{3}{*}{ Mechanical properties } & \multicolumn{4}{|c|}{ Components } \\
\hline & \multicolumn{2}{|c|}{ Vertebral body } & \multicolumn{2}{|c|}{ Disc } \\
\hline & Cortical bone & Cancellous bone & Annulus & Nucleus \\
\hline Young's modulus (MPa) & 11,000 & 100 & 10 & 1 \\
\hline Poisson's ratio & 0.31 & 0.3 & 0.45 & 0.45 \\
\hline Yield strength (MPa) & 110 & 4 & 2.6 & 0.2 \\
\hline
\end{tabular}




\section{Development of the FE model of the intact lumbar spine}

The finite element model of the lumbar spine developed from the 3D geometric model is shown in Fig. 4. Fig. 4A shows the anterior and lateral views of the model and the detailed nomenclature of bony and soft tissue elements is shown in Fig. 4B. The properties of the soft tissues were obtained from the literature [12-16] and the soft tissues were modeled using MAT 91 that represents an isotropic Mooney-Rivlin matrix with fiber reinforcement having strain energy characteristics resembling the qualitative material behavior of collagen. The material properties of the various soft tissues that were used in the present model are shown in Tables 2 and 3. Intervertebral discs were modeled using higher order tetrahedral elements with an average element edge length of $1.5 \mathrm{~mm}$. Ligaments and the cortical bone were modeled using shell elements. An intact (no fusion) lumbar spine model (L1 to S1) shown in Fig. 4 was used as the baseline model. The loads and boundary conditions applied are shown in Fig. 5. A load of magnitude $350 \mathrm{~N}$ representing upper body weight was applied at $200 \mathrm{~mm}$ cranial and $30 \mathrm{~mm}$ ventral to the T12/ L1 disk center and a compressive follower load of $500 \mathrm{~N}$ was applied to simulate the effect of local muscles. These loads were consistent to those used in the study by Calisse et al. [11] and Rohlmann et al. [17]. The facet joint load obtained in the simulation of the intact spine model at
L2-L3 interface was $43 \mathrm{~N}$ and this was comparable with the results reported in the literature [18]. The loads and boundary conditions that were used for the intact spine model and the models with surgical intervention simulations were same.

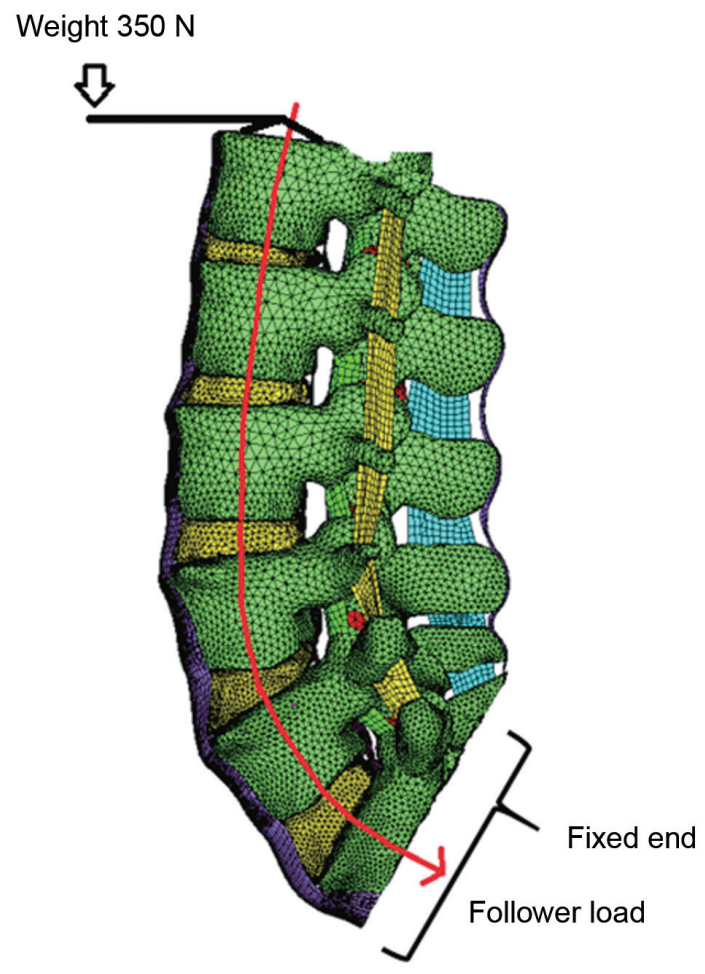

Fig. 5. Loads and boundary conditions.

Table 2. Material properties of soft tissues for use in MAT 91 (LS-DYNA material model)

\begin{tabular}{lccccccc}
$\begin{array}{l}\text { Material } \\
\text { properties }\end{array}$ & $\begin{array}{c}\text { Density } \\
\left(\mathrm{kg} / \mathrm{mm}^{3}\right)\end{array}$ & $\begin{array}{c}\text { Bulk modulus } \\
(\mathrm{MPa})\end{array}$ & $\begin{array}{c}\text { Poisson } \\
\text { ratio }(\mathrm{n})\end{array}$ & $\mathrm{C1}(\mathrm{MPa})$ & $\mathrm{C3}(\mathrm{MPa})$ & $\mathrm{C4}$ (MPa) & C5 (MPa) \\
\hline PLL & $1.00 \mathrm{E}-06$ & 3.2 & 0.4 & 0.17 & 0.60 & 11.88 & 19.24 \\
ITL & $1.00 \mathrm{E}-06$ & 4 & 0.4 & 0.095 & 0.8 & 4.077 & 14.05 \\
\hline SSL & $1.00 \mathrm{E}-06$ & 3.2 & 0.4 & 0.17 & 0.60 & 11.88 & 19.24 \\
\hline
\end{tabular}

PLL, posterior longitudinal ligament; ITL, inter transverse ligament; SSL, supra spinal ligament.

Table 3. Material properties of soft tissues for use in MAT 24 (LS-DYNA material model)

\begin{tabular}{|c|c|c|c|c|c|}
\hline $\begin{array}{l}\text { Material } \\
\text { properties }\end{array}$ & Density $\left(\mathrm{kg} / \mathrm{mm}^{3}\right)$ & $\begin{array}{l}\text { Young's modulus } \\
\text { (MPa) }\end{array}$ & Poisson ratio (n) & $\begin{array}{l}\text { Yield strength } \\
(\mathrm{MPa})\end{array}$ & $\begin{array}{c}\text { Tangent modulus } \\
\text { (MPa) }\end{array}$ \\
\hline ISL & $1.00 \mathrm{E}-06$ & 4.56 & 0.4 & 1.5 & 4 \\
\hline ALL & $1.00 \mathrm{E}-06$ & 11.4 & 0.4 & 27 & 10 \\
\hline $\mathrm{FC}$ & $1.00 \mathrm{E}-06$ & 22.8 & 0.4 & 27.4 & 20.9 \\
\hline LF & $1.00 \mathrm{E}-06$ & 5.7 & 0.4 & 1.5 & 5 \\
\hline
\end{tabular}

ISL, inter spinous ligament; ALL, anterior longitudinal ligament; FC, facet capsule; LF, ligment flavum. 


\section{Development of FE models of lumbar spine with sur- gical interventions}

Using the calibrated intact spine finite element model, various other models were developed to represent different types and levels of surgical interventions. These included-non-instrumented posterior fusion and instrumented posterior fusion; non-instrumented anterior fusion and instrumented anterior fusion. Fig. 6A shows the lumbar spine FE model pertaining to one, two and three level posterior fusion without instrumentation. In these models the postero-lateral bone graft has been added to fuse the relevant segment. In these models, the spinous processes, laminae, medial half of the facet joints, supraspinous ligament, interspinous ligament, intertransverse ligament, ligamentum flavum and part of the facet capsule were removed. Fig. $6 \mathrm{~B}$ shows the lumbar spine model pertain-

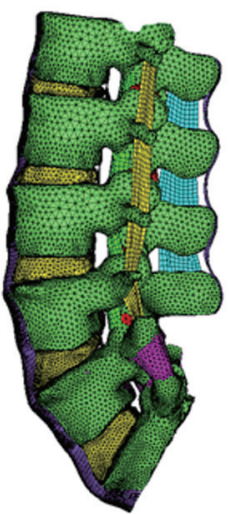

(A) One Level

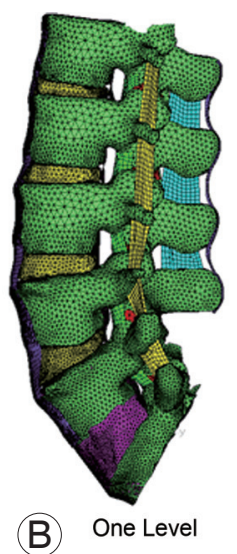

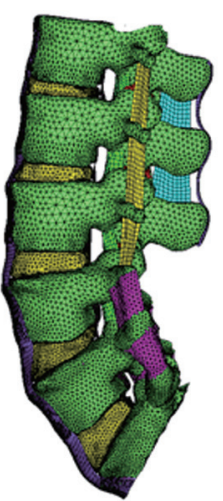

Two Level

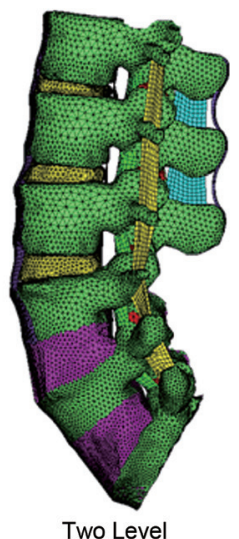

Two Level

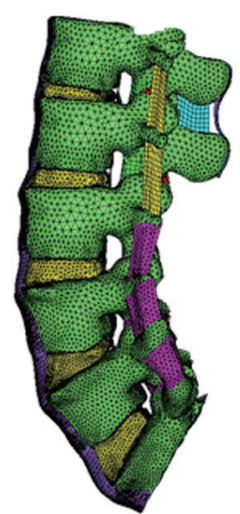

Three Level

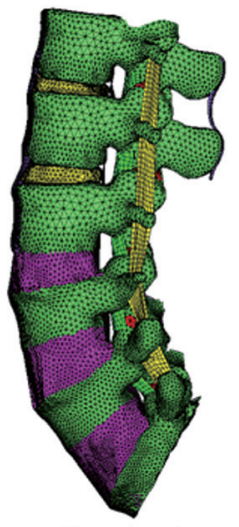

Three Level
Fig. 6. FE model of lumbar spine fusion without instrumentation. (A) One, two and three-level posterior fusion (with posterior decompression). (B) One, two and three-level anterior fusion (with posterior decompression). FE, finite element. ing to one, two and three level anterior fusion. In these models the anterior inter body bone graft has been added to fuse the relevant segment. In addition to the posterior decompression described above, anterior longitudinal ligament and the intervertebral disc were also removed (anterior lumbar inter body fusion) for these models.

The corresponding models with instrumentation are shown in Fig. 7. Fig. 7A shows the lumbar spine FE model pertaining to one, two and three level posterior fusion. In these models, posterior decompression has been performed and posterior pedicle screw instrumentation and postero-lateral bone graft have been added to fuse the relevant segment. Fig. 7B shows the lumbar spine model pertaining to one, two and three level anterior fusion. For these models, posterior decompression has been done and anterior instrumentation using cage with bone graft has been added to fuse the relevant segment. In these models,

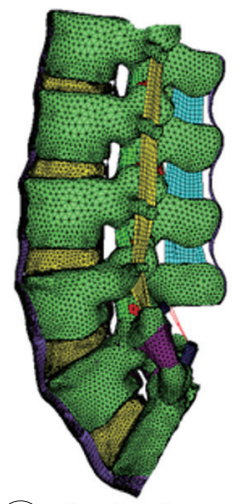

(A) One Level

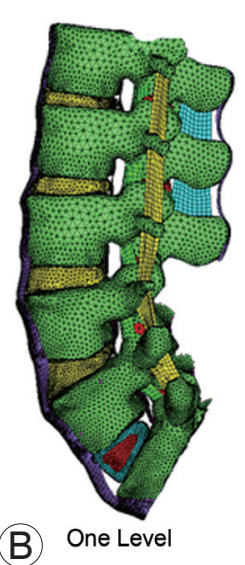

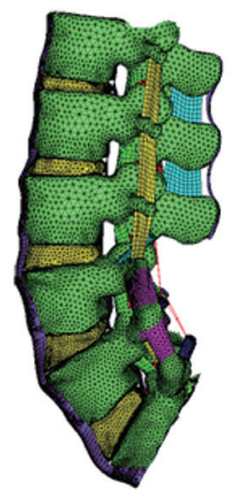

Two Level

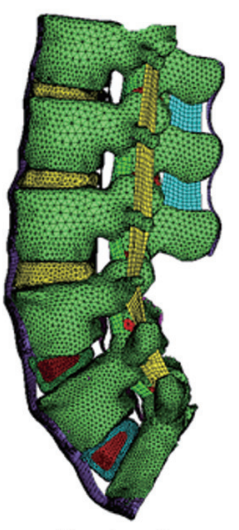

Two Level

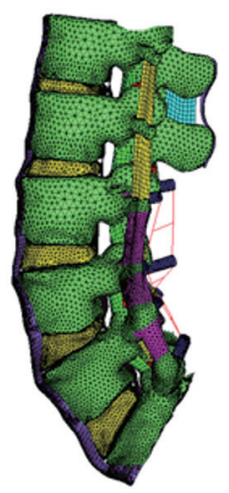

Three Level

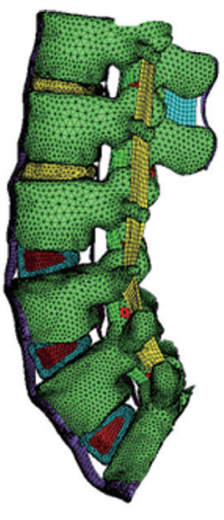

Three Level
Fig. 7. FE model of lumbar spine fusion with decompression and instrumentation. (A) One, two and three-level posterior instrumentation fusion. (B) One, two and three-level anterior instrumentation fusion. $\mathrm{FE}$, finite element. 
Table 4. Maximum von mises stress (MPa)

\begin{tabular}{|c|c|c|c|c|c|c|}
\hline \multirow{2}{*}{ Type of intervention } & \multicolumn{2}{|c|}{ L5-S1 (one level) } & \multicolumn{2}{|c|}{ L4-L5, L5-S1 (two levels) } & \multicolumn{2}{|c|}{$\begin{array}{c}\text { L3-L4, L4-L5, L5-S1 } \\
\text { (three levels) }\end{array}$} \\
\hline & Absolute value & $\%$ Increase & Absolute value & $\%$ Increase & Absolute value & $\%$ Increase \\
\hline $\begin{array}{l}\text { Maximum von mises stress } \\
(\mathrm{MPa}) \text { at the adjacent disc }\end{array}$ & \multicolumn{2}{|c|}{ L4-L5 } & \multicolumn{2}{|c|}{ L3-L4 } & \multicolumn{2}{|c|}{$\mathrm{L} 2-\mathrm{L} 3$} \\
\hline \multicolumn{7}{|l|}{ No fusion } \\
\hline Base line model & 2.23 & Not applicable & 1.41 & Not applicable & 1.04 & Not applicable \\
\hline \multicolumn{7}{|l|}{ Posterior fusion } \\
\hline $\begin{array}{l}\text { Posterior fusion without } \\
\text { instrumentation }\end{array}$ & 2.34 & 4.9 & 1.5 & 6.4 & 1.14 & 9.6 \\
\hline $\begin{array}{l}\text { Posterior fusion with } \\
\text { posterior instrumentation }\end{array}$ & 2.39 & 7.2 & 1.69 & 19.8 & 1.25 & 20.3 \\
\hline \multicolumn{7}{|l|}{ Anterior fusion } \\
\hline $\begin{array}{l}\text { Anterior fusion without } \\
\text { instrumentation }\end{array}$ & 2.40 & 7.6 & 1.70 & 20.5 & 1.71 & 64.4 \\
\hline $\begin{array}{l}\text { Anterior fusion with anterior } \\
\text { instrumentation }\end{array}$ & 2.46 & 10.3 & 1.71 & 21.3 & 1.9 & 82.6 \\
\hline
\end{tabular}

the spinous processes, laminae, medial half of the facet joints, supraspinous ligament, interspinous ligament, intertransverse ligament, ligamentum flavum and part of the facet capsule were removed.

\section{Results}

The magnitudes of the maximum stress values at the adjacent levels during different types of interventions at different levels of fusion were compared with the baseline no fusion model. The absolute values of the maximum Von Mises Stress at the adjacent discand the percentage increase over the baseline model are shown in Table 4. Fig. 8 shows the stress contours obtained in the intact spine model and the anterior and posterior fusion models with one, two and three-level instrumentation. The maximum stresses were located in the matrix of the annulus fibrosus of the disc.

\section{One-level fusion}

In the posterior fusion models, there was an increase by around 5\% in the stress levels in the adjacent disc following non-instrumented fusion. With the addition of instrumentation (pedicle screws), the adjacent level stresses increased by $7.2 \%$ over the baseline value. For the anterior fusion models, there was an increase by around $7.6 \%$ in the adjacent disc stresses following non-instrumented fusion. With the addition of anterior instrumentation (cage), there was a further increase in the adjacent disc stresses by $10.3 \%$ over the base line model.

\section{Two-level fusion}

In the non-instrumented posterior fusion, there was increase in the adjacent disc stress by $6.4 \%$. With the addition of instrumentation (pedicle screws), there was further increase in stress levels by $19.8 \%$ over the baseline value. In the non-instrumented anterior fusion models, there was an increase in the adjacent disc stresses by $20.5 \%$. With the addition of anterior instrumentation (cage), there was a significant increase in the adjacent disc stresses by $21.3 \%$.

\section{Three-level fusion}

In the non-instrumented posterior fusion, there was increase in the adjacent disc stress by $9.6 \%$. With the addition of instrumentation (pedicle screws), there was a significant increase in stress levels by $20.3 \%$ over the baseline value. In the anterior fusion models, there was a significant increase in the adjacent disc stresses by around $63 \%$ even without instrumentation. With the addition of anterior instrumentation (cage), there was an 

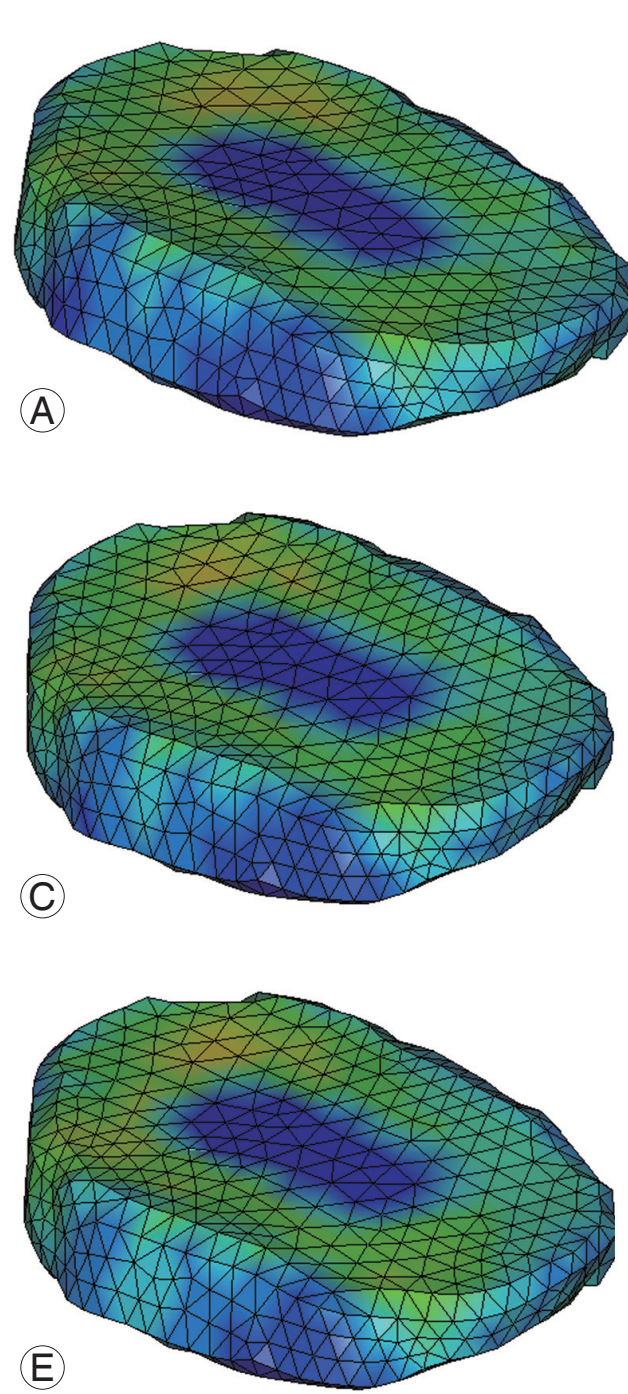

Fringe levels $1.199 \mathrm{e}+00$ $1.082 \mathrm{e}+00$ $9.653 \mathrm{e}-01$ $8.484 \mathrm{e}-01$ $7.315 \mathrm{e}-01$ $6.148 \mathrm{e}-01$ $4.979 \mathrm{e}-01$ $3.811 \mathrm{e}-01$ $2.643 \mathrm{e}-01$ $1.474 \mathrm{e}-01$ $3.061 \mathrm{e}-02$ increase in the adjacent disc stresses by $82.6 \%$ over the base line value.

\section{Discussion}

It is debatable whether ASD is a 'de novo' phenomenon that is caused by segmental spinal fusion per se or is simply an extension of the same disease process that affected other discs earlier. Two long-term studies on this subject arrived at differing conclusions. Hambly et al. [19] compared the incidence of ASD in patients who had undergone posterolateral non-instrumented lumbar fusion with the incidence of ASD in a group of ageand gendermatched patients who had low back pain but had not undergone surgery. Over a mean follow-up period of 22.6 years, they found similar incidence of ASD changes in both groups. Kumar et al. [3] compared the ASD changes

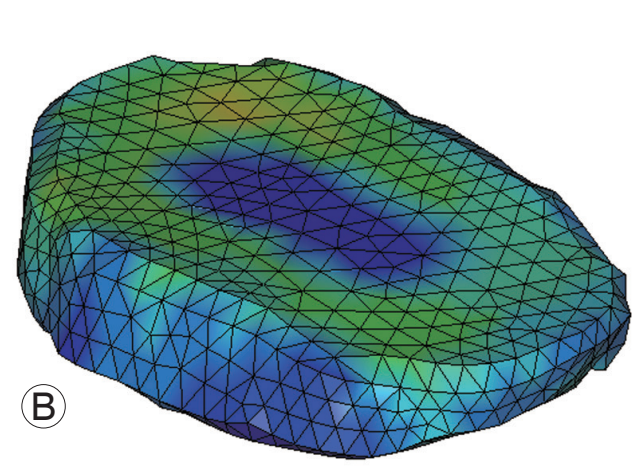

Fringe levels

$1.137 \mathrm{e}+00$

$1.025 \mathrm{e}+00$

$9.140 \mathrm{e}-01$

$8.028 \mathrm{e}-01$

$6.915 \mathrm{e}-01$

$5.803 \mathrm{e}-01$

$4.690 \mathrm{e}-01$

$3.578 \mathrm{e}-01$

$2.465 \mathrm{e}-01$

$1.353 \mathrm{e}-01$

$2.405 \mathrm{e}-02$

Fringe levels

$1.871 \mathrm{e}+00$

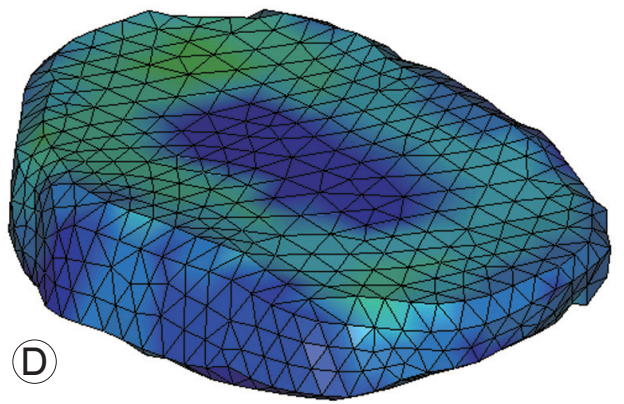

$1.686 \mathrm{e}+00$

$1.501 \mathrm{e}+00$

$1.316 \mathrm{e}+00$

$1.130 \mathrm{e}+00$

$9.451 \mathrm{e}-01$

$7.599 \mathrm{e}-01$

5.746e-01_

$3.894 \mathrm{e}-01$

2.042e-01

$1.897 \mathrm{e}-02$

Fig. 8. Stress plots for baseline and three-level fusion models. (A)

Baseline no-fusion. (B) Posterior fusion without instrumentation.

(C) Posterior fusion with instrumentation. (D) Anterior fusion without instrumentation. (E) Anterior fusion with instrumentation. in a cohort of patients who had undergone posterior midline fusion with another cohort of patients who had low back pain but had not undergone surgery. Over a minimum follow-up period of 30 years, they found that radiographic incidence of ASD was twice as high in the fusion group but there were no significant differences between the groups in terms of functional assessment.

The claim that spinal fusion is a causative factor in ASD is based on the observations of increased mechanical loading on the adjacent discs in earlier studies [20,21]. Some studies have estimated that stress on the adjacent disc increases by around $20 \%$ over the normal disc [22]. Biomechanical changes that have been implicated in the causation of ASD include increased intradiscal pressure in the adjacent disc, abnormal loading of the facet joints and compensatory increase in mobility in the adjacent segments following segmental fusion [6]. Biological fac- 
tors that have been implicated in the causation of ASD include advanced age of the patient, obesity and presence of preexisting degenerative changes in the adjacent discs $[23,24]$. Surgical factors that have been studied include the presence of instrumentation, length of fusion, frontal and sagittal plane malalignment and intra operative injury to facet joints [6,9]. In the present study, authors have assessed the surgical (iatrogenic) factors in the causation of increased stresses in the adjacent discs.

\section{Length of fusion}

Ghiselli et al. [8] and Pellise et al. [24] found no correlation between ASD and the length of fusion. Chen et al. [10] found that longer fusions were a risk factor for ASD, especially fusions up to L1 to L3 segments. Gillet [9] reported ASD changes in $32 \%$ of patients following single motion-segment fusion, 31\% ASD changes following double segment fusion and $66 \%$ ASD changes following triple segment fusion. The ASD changes were more severe and symptomatic following 2 and 3 segment fusions than with single segment fusions. In $11 \%$ of patients with single segment fusion, reoperation for ASD was required compared with $27 \%$ in the two segment fusion group and $33 \%$ in the three segment fusion group [9]. In the present study, the adjacent segment disc stresses increased with the length of fusion and this was true for all types of fusions (anterior/posterior, instrumented/non-instrumented). In the FE analysis study by Chen et al. [10] higher magnitudes of adjacent level stresses were found with longer anterior inter body fusions. Our study supports this finding not only in anterior inter body fusion but in all types of fusions. Length of fusion seems to be an independent risk factor for ASD regardless of other associated factors.

\section{Type of fusion}

Penta et al. [25] and Wai et al. [26] used MRI and functional outcome studies and reported a low incidence of ASD following anterior lumbar inter body fusion. Only $7.6 \%$ of patients required reoperation due to ASD and the authors concluded that ASD following anterior lumbar inter body fusion was more likely due to naturally induced degenerative changes rather than due to abnormal biomechanics following anterior fusion. Luk et al. [27] performed a radiographic study of spinal mobility in patients following anterior lumbar fusion. They found no increase in mobility at adjacent segments compared with healthy volunteers. In the present study, stresses in the adjacent discs showed comparable increases following both anterior as well as posterior fusions. Also, anterior fusion did not seem to offer protection against increased stresses in the adjacent segments. FE studies by Chen et al. [10] have also found significantly increased adjacent disc stresses following anterior inter body fusion.

\section{Effect of instrumentation on ASD}

Incidence of symptomatic ASD is said to be higher in patients with instrumented spinal fusion using pedicle screws compared to those with non-instrumented spinal fusion or fusion with implants other than pedicle screws [7]. Cakir et al. [28] reported no reduction in global range of motion (ROM) of the lumbar spine as well in the ROM of the adjacent segment following posterior dynamic stabilization without fusion. In the present study, instrumentation led to an increase in adjacent level stresses at all levels of fusion when compared with non-instrumented fusion. This was true for both anterior and posterior fusions.

Even though the adjacent disc degeneration may simply be a manifestation of the susceptibility to such degeneration in an individual patient, studies have shown that the incidence of ASD is higher following spinal fusion compared to patients without fusion. This implies that stresses on the adjacent discs are increased following segmental spinal fusion. Clinical studies reported so far seem to support this, but a comparison of the magnitudes of stresses following different levels of lumbar spinal fusion has not been reported until now.

\section{Conclusions}

The results of this finite element study suggest that length of fusion is a risk factor for ASD. Longer fusions, whether anterior/posterior or instrumented/non-instrumented are associated with increased stresses on the adjacent cephalad disc. Both anterior and posterior fusions showed comparable increase in adjacent level stresses at all levels of fusion. Instrumentation was associated with much higher magnitudes of adjacent level stresses compared with noninstrumented fusion. Thus, instrumentation and length of fusion seem to be most significant factors in increasing adjacent level stresses. 


\section{Conflict of Interest}

No potential conflict of interest relevant to this article was reported.

\section{References}

1. Ehni G. The role of spine fusion: question 9. Spine 1981;6:308-10.

2. Lehmann TR, Spratt KF, Tozzi JE, et al. Long-term follow-up of lower lumbar fusion patients. Spine (Phila Pa 1976) 1987;12:97-104.

3. Kumar MN, Jacquot F, Hall H. Long-term follow-up of functional outcomes and radiographic changes at adjacent levels following lumbar spine fusion for degenerative disc disease. Eur Spine J 2001;10:309-13.

4. Lee CK. Accelerated degeneration of the segment adjacent to a lumbar fusion. Spine (Phila Pa 1976) 1988;13:375-7.

5. Hilibrand AS, Robbins M. Adjacent segment degeneration and adjacent segment disease: the consequences of spinal fusion? Spine J 2004;4(6 Suppl): 190S-194S.

6. Park P, Garton HJ, Gala VC, Hoff JT, McGillicuddy JE. Adjacent segment disease after lumbar or lumbosacral fusion: review of the literature. Spine (Phila Pa 1976) 2004;29:1938-44.

7. Kumar MN, Baklanov A, Chopin D. Correlation between sagittal plane changes and adjacent segment degeneration following lumbar spine fusion. Eur Spine J 2001;10:314-9.

8. Ghiselli G, Wang JC, Bhatia NN, Hsu WK, Dawson EG. Adjacent segment degeneration in the lumbar spine. J Bone Joint Surg Am 2004;86:1497-503.

9. Gillet $\mathrm{P}$. The fate of the adjacent motion segments after lumbar fusion. J Spinal Disord Tech 2003;16:33845.

10. Chen CS, Cheng CK, Liu CL, Lo WH. Stress analysis of the disc adjacent to interbody fusion in lumbar spine. Med Eng Phys 2001;23:483-91.

11. Calisse J, Rohlmann A, Bergmann G. Estimation of trunk muscle forces using the finite element method and in vivo loads measured by telemeterized internal spinal fixation devices. J Biomech 1999;32:727-31.

12. Robertson D, Willardson R, Parajuli D, Cannon A, Bowden AE. The lumbar supraspinous ligament demonstrates increased material stiffness and strength on its ventral aspect. J Mech Behav Biomed Mater 2013;17:34-43.

13. Hortin M, Graham S, Boatwright K, Hyoung P, Bowden A. Transversely isotropic material characterization of the human anterior longitudinal ligament. J Mech Behav Biomed Mater 2015;45:75-82.

14. Kirby MC, Sikoryn TA, Hukins DW, Aspden RM. Structure and mechanical properties of the longitudinal ligaments and ligamentum flavum of the spine. J Biomed Eng 1989;11:192-6.

15. El-Rich M, Arnoux PJ, Wagnac E, Brunet C, Aubin $\mathrm{CE}$. Finite element investigation of the loading rate effect on the spinal load-sharing changes under impact conditions. J Biomech 2009;42:1252-62.

16. Cyron BM, Hutton WC. The tensile strength of the capsular ligaments of the apophyseal joints. J Anat 1981;132:145-50.

17. Rohlmann A, Bauer L, Zander T, Bergmann G, Wilke HJ. Determination of trunk muscle forces for flexion and extension by using a validated finite element model of the lumbar spine and measured in vivo data. J Biomech 2006;39:981-9.

18. Jaumard NV, Welch WC, Winkelstein BA. Spinal facet joint biomechanics and mechanotransduction in normal, injury and degenerative conditions. J Biomech Eng 2011;133:071010.

19. Hambly MF, Wiltse LL, Raghavan N, Schneiderman G, Koenig C. The transition zone above a lumbosacral fusion. Spine (Phila Pa 1976) 1998;23:1785-92.

20. Eck JC, Humphreys SC, Hodges SD. Adjacent-segment degeneration after lumbar fusion: a review of clinical, biomechanical, and radiologic studies. Am J Orthop (Belle Mead NJ) 1999;28:336-40.

21. Kim YE, Goel VK, Weinstein JN, Lim TH. Effect of disc degeneration at one level on the adjacent level in axial mode. Spine (Phila Pa 1976) 1991;16:331-5.

22. Weinhoffer SL, Guyer RD, Herbert M, Griffith SL. Intradiscal pressure measurements above an instrumented fusion. A cadaveric study. Spine (Phila Pa 1976) 1995;20:526-31.

23. Cheh G, Bridwell KH, Lenke LG, et al. Adjacent segment disease followinglumbar/thoracolumbar fusion with pedicle screw instrumentation: a minimum 5-year follow-up. Spine (Phila Pa 1976) 2007;32:22537.

24. Pellise F, Hernandez A, Vidal X, Minguell J, Martinez C, Villanueva C. Radiologic assessment of all unfused 
lumbar segments 7.5 years after instrumented posterior spinal fusion. Spine (Phila Pa 1976) 2007;32:5749.

25. Penta M, Sandhu A, Fraser RD. Magnetic resonance imaging assessment of disc degeneration 10 years after anterior lumbar interbody fusion. Spine (Phila $\mathrm{Pa}$ 1976) 1995;20:743-7.

26. Wai EK, Santos ER, Morcom RA, Fraser RD. Magnetic resonance imaging 20 years after anterior lum- bar interbody fusion. Spine (Phila Pa 1976) 2006;31: 1952-6.

27. Luk KD, Chow DH, Evans JH, Leong JC. Lumbar spinal mobility after short anterior interbody fusion. Spine (Phila Pa 1976) 1995;20:813-8.

28. Cakir B, Carazzo C, Schmidt R, Mattes T, Reichel H, Kafer W. Adjacent segment mobility after rigid and semirigid instrumentation of the lumbar spine. Spine (Phila Pa 1976) 2009;34:1287-91. 